\title{
Development and Validation of a Short Version Sport Orientation Questionnaire for Chinese Adolescents (SOQ-CA)
}

\author{
Jindong Chang ${ }^{1,3}$, Yali Yi ${ }^{2 *}$ and Naiqing Song ${ }^{3,45 *}$ \\ 1 School of Physical Education, Institute of Motor Quotient, Southwest University, Chongqing, China, ${ }^{2}$ School \\ of Mathematics and Statistics, Yulin Normal University, Yulin, China, ${ }^{3}$ School of Mathematics and Statistics, Southwest \\ University, Chongqing, China, ${ }^{4}$ Southwest University Branch, Collaborative Innovation Center of Assessment toward Basic \\ Education Quality, Beijing Normal University, Beijing, China, ${ }^{5}$ Key Liberal Arts Research Bases of Chongqing, Basic \\ Education Research Center, Southwest University, Chongqing, China
}

OPEN ACCESS

Edited by:

Mengcheng Wang,

Guangzhou University, China

Reviewed by:

Atta Abbas Naqvi,

University of Science Malaysia,

Malaysia

Haiyan Zhao,

Beijing Education Examinations

Authority, China

*Correspondence:

Yali $Y$

yiyali_ynu@163.com

Naiqing Song

songnq@swu.edu.cn

Specialty section:

This article was submitted to

Quantitative Psychology

and Measurement

a section of the journal

Frontiers in Psychology

Received: 01 February 2020

Accepted: 24 April 2020

Published: 17 June 2020

Citation:

Chang J, Yi Y and Song N (2020)

Development and Validation of a

Short Version Sport Orientation

Questionnaire for Chinese

Adolescents (SOQ-CA).

Front. Psychol. 11:1039.

doi: 10.3389/fpsyg.2020.01039
A noted decrease in adolescent physical activity in the past decade has resulted in an increase in health risks. Sport orientation correlates closely with physical activity. A sufficient assessment scale that measures an individual's sport orientation is important to measure an adolescent's physical inactivity. The purpose of this study was to develop and validate a short version of the Sport Orientation Questionnaire for Chinese Adolescents (SOQ-CA). Based on Gill's SOQ and previous literature, an initial 30-item questionnaire was developed to create the original SOQ-CA. A five-point Likert scale was used to measure by self-report. In this study, three surveys were conducted. Volunteer participants completed 1,235 valid questionnaires. The data of the first collection sample $(n=486)$ were split randomly into two groups, sample 1 ( $n=150)$ used for exploratory factor analysis (EFA) and sample $2(n=336)$ for confirmatory factor analysis (CFA). The data of the second $(n=377)$ and third $(n=372)$ collection samples were used to perform test-retest reliability, internal consistency, and CFA of the SOQ$\mathrm{CA}$. The SOQ-CA obtained good reliability and validity through both EFA and CFA. The development of the SOQ-CA provides an opportunity to develop further theories and practices regarding the assessment of both sport motivation and individual achievement orientation. The application of the SOQ-CA in China would be significant for monitoring the development of adolescent physical activity and aiding in the implementation of policies.

Keywords: Chinese adolescents, competitiveness, SOQ-CA, sport orientation, sports motivation

\section{INTRODUCTION}

Physical activity is important to adolescent growth and development in any country in the world (Brown et al., 2017). Physical inactivity in youth is a common problem globally, and China is no exception to this (World Health Organization [WHO], 2019). The bulletin of the State General Administration of Sport of China shows that, from 1978 to 2016, physical inactivity in Chinese youth has led to the serious decline of physical fitness (SGASC, 2018). This highlights 
the fact that we must figure out how to motivate youth participation in physical activity, to improve their physical fitness overall. Some researchers believe that there is a positive link between sport orientation and participation in physical activity (Marsh et al., 1995; Findlay and Coplan, 2008). Sport orientation is an important index that measures individual differences in sport achievement orientation (Gill and Dzewaltowski, 1988; Bowker et al., 2003). It is important to consider the definition of "fit" physical activity types and sport orientation (Kokaridas et al., 2009). One study has noted that "the fit between athleticism and sport orientation are important" (Findlay and Bowker, 2009). Some studies have explored the interaction between sport orientation and an individual's future competence, confidence, and connectedness (Perkins and Borden, 2004; Telama et al., 2006; Kjønniksen et al., 2009; Miller and Siegel, 2017). Some studies have also suggested that sport orientation may predict competitive anxiety (Jones and Swain, 1992; Daniel et al., 1999). One more recent study showed that fear of competition affects on youth health promotion (Tari-Keresztes et al., 2015). Therefore, revealing the mechanism involved in sport orientation will contribute to the exploration of the reasons for youth physical inactivity (Xu and Gao, 2018).

Previous research has proposed numerous different sport orientations theoretical models-both achievement- and goaloriented versions - and each model has had a related evaluation tool (Weiner, 1985; Lewthwaite and Piparo, 1993; Mills, 1996; Lata and Mondello, 2010; Gutiérrez et al., 2011; Han et al., 2015). Although the general consensus with these tools is that the measured objective of sport orientation exists, there have been different approaches in how to measure these constructs. For example, the Perceptions of Success Questionnaire (POSQ) and the Task and Ego Orientation in Sport Questionnaire (TEOSQ) have been used to evaluate individual differences in task and ego goal proneness (Duda, 1989; Roberts and Balagué, 1989; Lochbaum et al., 2016). The Competitive Orientation Inventory (COI) was developed to measure an athlete's self-confidence and competitiveness orientation (Vealey, 1986). The Sport Orientation Questionnaire (SOQ) and the Achievement Motives Scale-Sport (AMS-Sport; German version) were both designed to assess sport-specific achievement (motivation) orientations (Gill and Deeter, 1988; Elbe, unpublished). Today, the Gill's SOQ has been used extensively to assess sport-specific orientation (Gill et al., 1996; Skordilis and Stavrou, 2005; Skordilis et al., 2006; Shihui et al., 2007; Swann et al., 2015). Although the measurement constructs of the Gill's SOQ and the other tools differ, all five questionnaires evaluate the same achievement goal orientation (Duda and Whitehead, 1998; Hanrahan and Biddle, 2002). As the Gill's SOQ has been shown to effectively measure competitiveness and achievement behavior in sport and exercise settings, the present study chose to revise the SOQ as a measurement tool of sport orientation for Chinese adolescents (Lihui, 2004).

Gill's SOQ is "a multidimensional, sport-specific measure of individual differences in sport achievement orientation" (Gill and Deeter, 1988). It is a 25-item scale that includes three subscales: competitiveness orientation, win orientation, and goal orientation (Gill and Deeter, 1988). The competitiveness orientation subscale consists of 13 items that measure participants' feelings regarding their competition with others (desire for competition). The win orientation subscale comprises six items that measure participants' perceptions regarding success in competition (focus on winning). The goal subscale is made of six items that assess participants' feelings regarding their sports performance (personal performance). The scale is rated on a five-point Likert scale ( 1 = strongly disagree, $5=$ strongly agree) and the level of internal consistency is high, with a Cronbach's $\alpha$ of 0.88 .

Gill's SOQ has been used widely since its development to assess and predict sport achievement orientation. Trembath et al. (2002), Biddle et al. (2003), Kolt et al. (2004), Daniels et al. (2005), Sheikh et al. (2011), Farshad et al. (2013), and BaronThiene and Alfermann (2015) have all reported appropriate models of the scale and confirmed that the SOQ was effective at measuring certain athletic tendencies among numerous sample communities. Studies have shown that there are significant differences between the goal task and participation motivation among different sports levels of athletes, such as amateur athletes and professional athletes (Koumpoula et al., 2011; Alfermann et al., 2013). Sports motivation, sports participation, and sports competitiveness have been used and have been shown to be effective models for evaluating certain athletes (e.g., elite athletes or disabled athletes) (Zarghmi et al., 2010; Scoffier et al., 2012; Allen et al., 2015). However, there are only a few scholars who have focused specifically on adolescent sport orientation (Vilkas and Mëlinis, 2017; Chang et al., 2018).

There is already a large amount of published literature that has examined sport orientation and sport motivation that focuses on goal orientation or achievement motivation constructs (Dweck, 1986; Maehr and Braskamp, 1986; Vealey, 1986; Stipek, 1988; Nicholls, 1989; Ames, 1992; Roberts, 1992; Duda, 1993; Treasure and Roberts, 1994). Past research has used both exploratory (Duda, 1989; Duda and White, 1992; Newton and Duda, 1993; Kim and Gill, 1997; Skordilis et al., 2001; Wakayama et al., 2002; Tari-Keresztes et al., 2015) and confirmatory (Kang et al., 1990; Li and Tang, 1990; Seifriz et al., 1992; Hayashi and Weiss, 1994; Marsh, 1994; Chi and Duda, 1995; Duda, 1995; Lerner and Locke, 1995; Skordilis et al., 2001; Hanrahan and Biddle, 2002) factor analysis to test the construct of the Gill's SOQ. However, sample participants have been largely sourced from the United States, Australia, or the European Union. Very few studies have reported results from Asian or Middle Eastern contexts, though there has been published research from Iran (Farshad et al., 2013), Japan (Wakayama et al., 2002), and China (Kang et al., 1990; Chang et al., 2018).

Gill's SOQ has already been adapted to create a Chinese version of the measurement, revised and validated using college students and elite athletes ( $\mathrm{Li}$ and Tang, 1990). However, a recent study has reported that Gill's SOQ (Chinese version) cannot adequately distinguished Chinese youth sport orientation, particularly in differentiating between competitiveness and win orientations (Chang et al., 2018). Additionally, an earlier study found that Gill's SOQ (Japanese version) differed when compared back to the original English-language version in terms of competitiveness (Wakayama et al., 2002). One study in Taiwan 
found sex differences only in competitiveness (Kang et al., 1990), while another study on Koreans indicated that there was no significant gender difference in the sport orientation (Kim and Gill, 1997). The differences in sample demographics and cultures may lead to differences in the results and their meanings when comparing translated versions of the SOQ to the original English version (White et al., 1998). Consequently, in revising the Chinese version of the SOQ, it is important that study sample demographics, and cultural differences must be considered first (Bernstein and Nunnally, 1994). The purpose of the present study then was to develop and validate the Chinese version of the SOQ by relating responses to items adapted from Gill's original SOQ (1988) as well as to external criteria, specifically to multiple dimensions of subjects' physical self-concepts.

\section{MATERIALS AND METHODS}

\section{Participants}

The participants consisted of two groups. The first group was part of a 30-item SOQ exploration phase, made up of a total of 486 individuals (male $=249$, female $=237$ ). Their age ranged from 12 to 16 years $(13.63 \pm 1.38)$. The participants of group 1 were split randomly using a computergenerated randomization sequence (GraphPad Software, Inc.) into two subgroups with the approximate ratio of 1:2 (i.e., sample $1=150$ cases, sample $2=336$ cases) (Sum et al., 2016), in which the subsample size satisfied the minimum amount of data required (Paiva et al., 2014). Participants in group 2 performed two tests. The subgroup that completed first test was named sample $3(n=377)$, and the subgroup that completed the second test was sample $4(n=372)$. Group 2 participants completed the 13-item SOQ-CA, and comprised 338 participants (male $=180$, female $=158$, age $=13.18 \pm 0.86$ ). Considering that the academic performance of Chinese urban school students is better than that of rural schools, the universality of the questionnaire was verified by using samples from two different regional schools. The participants in group 1 came from two middle schools in central Chongqing, China. The participants in group 2 came from three middle schools in the urban-rural junction in Chongqing, China (Table 1).

\section{Procedures}

All participants voluntarily agreed to take part in the study. As they were all minors, their guardians approved their participation

TABLE 1 | Basic characteristics of participants.

\begin{tabular}{lcccc}
\hline & Group 1 & Sample 1 & Sample 2 & Sample 3/4 \\
\hline Sex (Male/Female) & $249 / 237$ & $69 / 81$ & $180 / 156$ & $180 / 158$ \\
Age (Years) & $12-16$ & $12-16$ & $12-16$ & $12-16$ \\
BMl & $19.8 \pm 3.65$ & $19.8 \pm 3.87$ & $19.8 \pm 3.57$ & $19.7 \pm 4.16$ \\
Sports level (active) & 47 & 17 & 30 & 47 \\
Sports level (general) & 439 & 133 & 306 & 291
\end{tabular}

in the study by signing the research information letter. The questionnaire was distributed and collected with the assistance of the class teacher and was completed in the classroom before school extracurricular activities. The researchers were responsible for answering any questions raised by the participants. The average questionnaire completion time was $6 \mathrm{~min}$. The data for group 1 (samples 1 and 2) were collected between March and June of 2018, and all these participants agreed to complete the 30 -item SOQ and AMS-Sport questionnaires. Although the data collection lasted 2 months, samples 1 and 2 were not involved in a time interval because these data were split from group 1 . The data for samples 3 and 4 were collected during May and June of 2019, with these data collected at 15-day intervals. These participants completed the 13-item Chinese version SOQ.

\section{Measures}

\section{Scale Development}

First, Gill's SOQ English version was translated to create the SOQ Chinese version. Based on the literature review and interviews with sports motivation research experts, 14 items were added, making the SOQ Chinese version a 39-item questionnaire. Once this was developed, it was submitted to three professional researchers for conceptual evaluation: one researcher with experience in sports exercise and adolescent sports motivation; one with experience in adolescent sports motivation and the development and validation of instruments; and one with experience in sports competitiveness, adolescent health, and goal orientation. The SOQ Chinese version was evaluated by all three researchers from the following perspectives: semantic equivalence, conceptual scope, clarity, readability, relevance, and conciseness (Patton, 1999; Yin, 2002; Paiva et al., 2014). During this process, seven items were deleted because of low relevance, and four items were merged into two items due to lack of clarity. The final questionnaire, then, including 30 items (see Table 2). After all three researchers agreed that none of the items required further modification, the SOQ Chinese version was sent to a linguistics professor to check its grammar.

Second, an interview was conducted using a focus group composed of a sample of 12 adolescents (group 1 with two schools, group 2 with one school, and each school with four students) to test their understanding of the questionnaire items (Boynton and Greenhalgh, 2004). All participants were chosen randomly, following the criteria of having regular enrollment in school, being 12-16 years of age, having received authorization from their parents through a signed statement of informed consent, and having received the student's agreement to participate. Focus group participants shared their views on sport orientation and discussed the relationship between sports goals, sports motivation, sports competitiveness, and sport orientation. The researchers used structured questions to guide the focus group discussion, which helped to identify critical points such as competitiveness, orientation, goal, and motivation to aid in the instrument's development. After the focus group, the questionnaire was revised using the suggestions proposed by the interviewees. At this point, the new version of the instrument was sent to two external researchers for further review. 
TABLE 2 | SOQ Chinese version items containing 30 questions on sport orientation.

\begin{tabular}{|c|c|c|c|}
\hline Sign & S1 & S2 & Items \\
\hline A1 & / & $\mathrm{C}^{\mathrm{a}}$ & I am confident when exercising. 我运动时充满自信 \\
\hline A2 & / & $G^{a}$ & I think sports are important. 我认为运动是重要的 \\
\hline A3 & C & $\mathrm{C}^{\mathrm{b}}$ & I am a competitive person. 我是一名有竞争力的人 \\
\hline A4 & G & $G^{c}$ & I set goals for myself when competing. 竞赛时, 我为自己设定目标 \\
\hline A5 & G & $\mathrm{G}^{\mathrm{c}}$ & I try my hardest to win the game. 比赛时, 我尽力去赢 \\
\hline A6 & / & $W^{a}$ & Beating my opponent is very important for me. 对我来说, 击败对手是很重要的 \\
\hline A7 & $\mathrm{C}$ & $\mathrm{C}^{\mathrm{b}}$ & I look forward to competing. 我期待着比赛 ( 竞赛) \\
\hline A8 & C & $\mathrm{C}^{\mathrm{b}}$ & I am most competitive when I try to achieve personal goals. 当我努力实现个人目标时, 我最有竞争力 \\
\hline A9 & C & $\mathrm{C}^{\mathrm{b}}$ & I enjoy competing against others. 我享受跟他人比赛 ( 竞赛 ) \\
\hline A10 & W & $W^{b}$ & I hate to lose. 我讨厌输 \\
\hline A11 & / & $\mathrm{G}^{\mathrm{a}}$ & Sports make me vibrant. 运动使我充满活力 \\
\hline A12 & G & $\mathrm{G}^{\mathrm{b}}$ & I try my hardest when I have a specific goal. 当我有具体目标时, 我尽最大努力完成 \\
\hline A13 & C & $\mathrm{C}^{\mathrm{C}}$ & My sports goal is to become a winner. 我运动的目标是成为一名获胜者 \\
\hline A14 & W & $W^{c}$ & I am delighted when I win. 赢了, 我感到很高兴 \\
\hline A15 & C & $\mathrm{G}^{\mathrm{b}}$ & I want to be successful in sports. 我想在运动中取得成功 \\
\hline A16 & G & $G^{c}$ & Performing to the best is very important to me. 运动中表现出色对我是很重要的 \\
\hline A17 & C & $\mathrm{C}^{\mathrm{C}}$ & I work hard for success in sports. 我为运动成功而努力 \\
\hline A18 & W & $W^{b}$ & Losing upsets me. 比赛失利让我烦恼 \\
\hline A19 & C & $\mathrm{C}^{\mathrm{b}}$ & The best test of my ability is competing against others. 测试我运动能力最好的办法是与他人比赛( 竞赛) \\
\hline A20 & G & $\mathrm{G}^{\mathrm{b}}$ & Reaching personal performance goals is very important to me. 实现个人的表现目标对我是很重要的 \\
\hline A21 & C & $\mathrm{C}^{\mathrm{C}}$ & I thrive on the opportunity to test my skills in competition. 我渴望与对手比赛 ( 竞赛) 测试我的技能 \\
\hline A22 & / & $W^{a}$ & I do my best to perform when I win. 获胜时, 我尽全力发挥自己的水平 \\
\hline A23 & C & $\mathrm{C}^{\mathrm{b}}$ & I perform my best when I am competing against an opponent. 当我与对手竞赛时, 我发挥最好 \\
\hline A24 & G & $G^{b}$ & The best way to determine my ability is to set a goal and try to reach it. 测试我能力的最好方法是设定目标并实现 \\
\hline A25 & C & $\mathrm{C}^{\mathrm{C}}$ & I want to be the best whenever I compete. 每次参加比赛我都想做的最好 \\
\hline A26 & W & $W^{c}$ & I think winning is important. 我认为获胜很重要 \\
\hline $\mathrm{A} 27$ & W & $W^{c}$ & I think winning makes me happy. 我认为获胜使我形 \\
\hline A28 & $\mathrm{C}$ & $\mathrm{G}^{\mathrm{C}}$ & I try my hardest to be a successful sportsman. 我尽最大努力成为一名杰出的运动者 \\
\hline A29 & G & $\mathrm{G}^{\mathrm{C}}$ & I get development in the competition. 我在竞赛中得到发展 \\
\hline A30 & W & $W^{b}$ & Scoring more points than the opponent is important to me. 比对手得分高对我更重要 \\
\hline
\end{tabular}

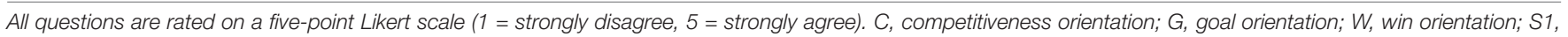
factor distribution of Gill's SOQ; S2, factor distribution of new SOQ Chinese version. ${ }^{a}$ The new statement. ${ }^{b}$ The original statement. ${ }^{c}$ The changed statement.

Third, a 30-item preliminary Chinese version of SOQ was developed (see Table 2). The 30-item version included the translated items from Gill's SOQ-of which 13 items that were left unchanged (items 3, 7, 8, 9, 10, 12, 15, 18, 19, 20, 23, 24, and 30 ), and 12 items that were revised (items $4,5,13,14,16$, $17,21,25,26,27,28$, and 29) - and included five additional items (items 1, 2, 6, 11, and 22). With regard to the revised items, some clarifications were added to items because of linguistic details of the Chinese language (i.e., "I think" was added to item 25), some changes were to add objects (i.e., "the game" was inserted into item 5), and some questions underwent major changes (i.e., item 27 changed "I have the most fun when I win" to "I think winning makes me happy"). The five new items were designed to effectively distinguish between goal orientation (items 2 and 11) and win orientation (items 6 and 22), and one final item to examine competitive factors (item 1 ).

\section{Reliability}

Test-retest and internal consistency were used in this study to verify the reliability of the SOQ-SA (Singh et al., 2011; Mehta et al., 2018). In general, $\alpha$ coefficients above 0.70 indicate acceptable (Barker et al., 1994). In evaluating the internal consistency, items with an item-to-total correlation of less than 0.20 were removed (McGraw and Wong, 1996).

\section{Validity}

The content validity of the questionnaire was performed by nine psychology professors with experience in sport motivation and sport orientation studies (Paiva et al., 2014). Professors were asked to review each item in the questionnaire and evaluate their relevance to the measured objects, clarity, and conciseness of each item.

Exploratory factor analysis (EFA) was applied to evaluate the questionnaire's construct validity. Bartlett's test and the KaiserMeyer-Olkin (KMO) measure were performed to test whether the data were appropriate for factor analysis. KMO values above 0.7 indicated that the condition for factor analysis was met (Bolarinwa, 2015). Generally, for a sample of 150 individuals, factor loadings greater than 0.50 are considered significant (Paiva et al., 2014). Factors were extracted considering eigenvalues greater than one and orthogonal rotation was performed using the varimax and direct oblimin method (Esbensen et al., 2002). If 
similar items displayed the load under different factors, the items would be deleted (Auxter et al., 2005).

The criterion-related validity between achievement orientations (AMS-Sport) and the SOQ-CA was analyzed based on sample 1 and sample 2. The AMS-Sport consists of two components: hope for success (HS) and fear of failure (FF). Each component has 15 items. The sum of the scores for each item is the total achievement motivation. Cronbach's $\alpha$ of the AMS-Sport was 0.90, and the measure's test-retest reliability was 0.71 (Elbe and Wenhold, 2005).

\section{Data Analysis}

Researchers analyzed any missing values in returned questionnaires. Frequency statistics showed that there were
36 cases in which some values were missing. Researchers used the mean to estimate missing values, allowing for all survey data collected to be included in the analysis (Field, 2009).

Exploratory factor analysis was performed on the data from sample 1, using IBM SPSS 24.0. Confirmatory factor analysis (CFA) was performed on the data from samples 2, 3, and 4, using AMOS 24.0 (SPSS Inc., Chicago, IL, United States). In the CFA verification, values for comparative fit index (CFI), goodness of fit index (GFI), Normed fit index (NFI), and TuckerLewis index (TLI) were all greater than 0.90 , which meant that the model was considered to be a good fit (Pons et al., 2006). For the root mean square error of approximation (RMSEA), a value of 0.06 suggests a good fit, and 0.08 is an acceptable fit (Bentler and Bonett, 1980).

TABLE 3 | Means and standard deviations of SOQ-CA.

\begin{tabular}{|c|c|c|c|c|c|c|c|c|}
\hline \multirow[t]{2}{*}{ Item } & \multicolumn{2}{|c|}{ Sample $1(n=150)$} & \multicolumn{2}{|c|}{ Sample $2(n=336)$} & \multicolumn{2}{|c|}{ Sample $3(n=338)$} & \multicolumn{2}{|c|}{ Sample $4(n=338)$} \\
\hline & $M$ & $S D$ & $M$ & $S D$ & $M$ & $S D$ & $M$ & $S D$ \\
\hline $\mathrm{A} 2$ & 4.33 & 1.14 & 4.28 & 1.19 & 4.37 & 0.93 & 4.46 & 0.90 \\
\hline A4 & 3.87 & 1.29 & 3.77 & 1.33 & 3.91 & 1.15 & 3.89 & 1.16 \\
\hline A5 & 4.39 & 1.07 & 4.12 & 1.26 & 4.28 & 1.00 & 4.35 & 0.99 \\
\hline A6 & 3.26 & 1.33 & 3.10 & 1.44 & 3.28 & 1.33 & 3.24 & 1.33 \\
\hline A7 & 3.33 & 1.40 & 3.13 & 1.47 & 3.31 & 1.36 & 3.28 & 1.36 \\
\hline A8 & 3.52 & 1.32 & 3.30 & 1.33 & 3.49 & 1.19 & 3.51 & 1.19 \\
\hline A9 & 3.47 & 1.33 & 3.40 & 1.43 & 3.55 & 1.25 & 3.53 & 1.31 \\
\hline A10 & 3.34 & 1.46 & 3.16 & 1.47 & 3.30 & 1.39 & 3.33 & 1.41 \\
\hline A11 & 3.75 & 1.45 & 3.79 & 1.33 & 3.87 & 1.20 & 3.92 & 1.16 \\
\hline A14 & 2.43 & 1.44 & 2.25 & 1.41 & 2.41 & 1.39 & 2.45 & 1.35 \\
\hline A18 & 2.99 & 1.42 & 2.94 & 1.44 & 3.07 & 1.33 & 3.10 & 1.31 \\
\hline A26 & 3.20 & 1.44 & 3.10 & 1.47 & 3.24 & 1.39 & 3.26 & 1.36 \\
\hline A30 & 2.71 & 1.44 & 2.56 & 1.39 & 2.78 & 1.35 & 2.67 & 1.31 \\
\hline Total & 44.59 & 17.52 & 42.91 & 17.96 & 44.86 & 16.27 & 44.99 & 16.14 \\
\hline
\end{tabular}

TABLE 4 | Factor structures by exploratory factor analysis and reliability $(n=150)$.

\begin{tabular}{|c|c|c|c|c|c|c|c|c|c|c|c|}
\hline \multirow[t]{2}{*}{ Sign } & \multirow[t]{2}{*}{ Items } & \multicolumn{2}{|c|}{ Win } & \multicolumn{2}{|c|}{ Goal } & \multicolumn{2}{|c|}{ Competitiveness } & \multirow[t]{2}{*}{ Var TVE\% } & \multirow[t]{2}{*}{ ITC-S } & \multirow[t]{2}{*}{ ITC-F } & \multirow[t]{2}{*}{$\alpha$} \\
\hline & & Var & Olb & Var & Olb & Var & Olb & & & & \\
\hline A10 & I hate to lose. & 0.77 & 0.80 & 0.09 & 0.00 & 0.02 & -0.08 & & 0.76 & 0.59 & \\
\hline A14 & I am delighted when I win. & 0.80 & 0.83 & -0.00 & -0.15 & 0.16 & 0.10 & & 0.80 & 0.63 & \\
\hline A18 & Losing upsets me. & 0.76 & 0.77 & 0.07 & -0.07 & 0.21 & 0.13 & & 0.78 & 0.66 & \\
\hline A2 & I think sports are important. & 0.16 & 0.04 & 0.81 & 0.86 & 0.12 & -0.09 & 21.09 & 0.81 & 0.61 & 0.83 \\
\hline A4 & I set goals for myself when competing. & 0.07 & -0.08 & 0.80 & 0.81 & 0.32 & 0.16 & & 0.86 & 0.64 & \\
\hline A5 & I try my hardest to win the game. & 0.24 & 0.12 & 0.72 & 0.70 & 0.28 & 0.11 & & 0.80 & 0.68 & \\
\hline A11 & Sports make me vibrant. & 0.10 & -0.03 & 0.72 & 0.72 & 0.29 & 0.13 & & 0.82 & 0.61 & \\
\hline A7 & I am looking forward to competing. & 0.19 & 0.08 & 0.26 & 0.06 & 0.79 & 0.80 & 17.54 & 0.86 & 0.65 & 0.81 \\
\hline
\end{tabular}

a, Cronbach's $\alpha$; ITC-F, Item-Total Correlation (full scale); ITC-S, Item-Total Correlation (subscales); TVE\%, Total Variance Explained. Bold numbers represent significant correlation in this dimension $(p<0.001)$. 
TABLE 5 | Correlations among variables in samples 1, 2, 3, and 4.

\begin{tabular}{|c|c|c|c|c|c|c|c|}
\hline Sample $1(n=150)$ & Sex & Age & BMI & Group & Win & Goal & Competitiveness \\
\hline Win & 0.045 & $0.512^{\star \star}$ & 0.022 & $-0.362^{\star \star}$ & & & \\
\hline Goal & 0.051 & $0.433^{\star \star}$ & 0.127 & $-0.198^{\star \star}$ & $0.370^{\star \star}$ & & \\
\hline Competitiveness & -0.119 & $0.404^{\star \star}$ & -0.018 & $-0.371^{\star \star}$ & $0.360^{\star \star}$ & $0.604^{\star \star}$ & \\
\hline $\mathrm{SOQ}$ & 0.008 & $0.584^{\star \star}$ & 0.053 & $-0.400^{\star \star}$ & $0.836^{\star \star}$ & $0.768^{\star \star}$ & $0.739^{\star \star}$ \\
\hline \multicolumn{8}{|l|}{ Sample $2(n=336)$} \\
\hline Win & -0.075 & $0.351^{\star \star}$ & -0.022 & $-0.306^{\star \star}$ & & & \\
\hline Goal & -0.057 & $0.328^{\star \star}$ & -0.059 & $-0.148^{\star \star}$ & $0.415^{\star \star}$ & & \\
\hline Competitiveness & -0.116 & $0.416^{\star \star}$ & -0.015 & $-0.295^{\star \star}$ & $0.446^{\star \star}$ & $0.722^{\star \star}$ & \\
\hline SOQ & -0.097 & $0.438^{\star \star}$ & -0.038 & $-0.312^{\star \star}$ & $0.841^{\star \star}$ & $0.806^{\star \star}$ & $0.867^{\star \star}$ \\
\hline \multicolumn{8}{|l|}{ Sample $3(n=338)$} \\
\hline Win & 0.022 & $0.228^{\star \star}$ & 0.050 & $-0.337^{\star *}$ & & & \\
\hline Goal & -0.037 & 0.081 & 0.049 & $-0.203^{\star \star}$ & $0.196^{\star \star}$ & & \\
\hline Competitiveness & -0.025 & $0.167^{\star \star}$ & -0.010 & $-0.206^{\star \star}$ & $0.305^{\star *}$ & $0.537^{\star \star}$ & \\
\hline SOQ & -0.006 & $0.233^{\star \star}$ & 0.046 & $-0.359^{\star \star}$ & $0.827^{\star \star}$ & $0.645^{\star \star}$ & $0.713^{\star \star}$ \\
\hline \multicolumn{8}{|l|}{ Sample 4 ( $n=338)$} \\
\hline Win & 0.030 & $0.223^{\star \star}$ & 0.032 & $-0.361^{\star \star}$ & & & \\
\hline Goal & -0.007 & 0.084 & 0.100 & $-0.211^{\star \star}$ & $0.238^{\star \star}$ & & \\
\hline Competitiveness & 0.022 & $0.130^{*}$ & 0.028 & $-0.230^{\star \star}$ & $0.291^{\star \star}$ & $0.565^{\star \star}$ & \\
\hline SOQ & 0.024 & $0.215^{\star \star}$ & 0.064 & $-0.381^{\star \star}$ & $0.821^{\star \star}$ & $0.685^{\star \star}$ & $0.714^{\star \star}$ \\
\hline
\end{tabular}

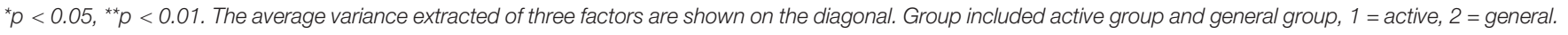

\section{RESULTS}

\section{Descriptive Statistics}

Table 3 shows the means and standard deviations of the SOQ-CA for all four samples.

\section{Exploratory Factor Analysis}

The initial questionnaire consisted of 30 items. The data from the first sample $(n=150)$ on the 30 items were evaluated by EFA (see Table 1). Seventeen items were removed after EFA, and 13 items were retained (see Table 4). The 13-item questionnaire demonstrated item-total correlations ranging from 0.59 to 0.71 ; the $\mathrm{KMO}$ index was 0.86 , Bartlett's test of sphericity proved to be significant $(p<0.001)$, and Cronbach's $\alpha$ coefficient for the total scale was 0.88 (see Table 4).

Exploratory factor analysis of the 13-item questionnaire produced three factors: win orientation, goal orientation, and competitiveness orientation. The win orientation factor included six variables (i.e., items $6,10,14,18,26$, and 30 ), the goal orientation factor included four variables (i.e., items 2, 4, 5, and 11), and the competitiveness orientation factor included three variables (i.e., items 7, 8, and 9). This means EFA resulted in the SOQ-CA containing 12 fewer items than Gill's SOQ (1988). Decreasing item numbers boosted the measurement's efficiency, but the reliability of the questionnaire required further verification (Petróczi, 2007; Manouchehri and Tojari, 2013). The total variance explained of each factor is shown on the diagonal in Table 4. These three factors explained $66.16 \%$ of the variance in the data. The win orientation alone explained $27.53 \%$ of the overall variability in the data; goal orientation explained $21.09 \%$ of the overall variability, and competitiveness orientation explained $17.54 \%$ of the overall variability (see Table 4). The correlations among the three facets of the four samples are also shown in Table 5. The pattern shown is generally consistent between both samples. Age is positive relation with the SOQ-CA $(p<0.01)$; group is negative relation $(p<0.01)$. However, sex is shown no related to the SOQ-CA in all four samples.

Meanwhile, to assess the fit of factor models, we examined the differences between the model-based correlations and the observed correlations three-factor model, which showed that $69 \%$ of the residuals were less than 0.1 (Cronbach, 1951). Regarding the internal consistency of three factors, all factors showed that Cronbach's alpha above 0.70 was sufficiently good (see Table 4).

\section{Confirmatory Factor Analysis}

The data from sample $2(n=336)$, sample $3(n=338)$, and sample $4(n=338)$ were used to validate and confirm the three-factor structure produced by the previous EFA. The results of the CFA indicated that the three-factor model had an adjusted model fit indices: sample $2\left(\chi^{2} / d f=150.458 / 62=2.427, p<0.001\right)$, $\mathrm{CFI}=0.96, \mathrm{GFI}=0.94, \mathrm{NFI}=0.93, \mathrm{TLI}=0.95, \mathrm{RMSEA}=0.065$; sample $3\left(\chi^{2} / d f=153.978 / 62=2.484, p<0.001\right), \mathrm{CFI}=0.93$, GFI $=0.94, \mathrm{NFI}=0.89, \mathrm{TLI}=0.92, \mathrm{RMSEA}=0.066$; sample $4\left(\chi^{2} / d f=143.149 / 62=2.309, p<0.001\right)$, CFI $=0.94$, GFI $=0.94$, NFI $=0.90$, TLI $=0.93$, RMSEA $=0.062$. The indicators showed that all the model fitting indices met the standard. Furthermore, the item loadings ranged from 0.52 to 0.82 (see Figures $1 \mathrm{~A}-\mathrm{C}$ ) and all were above the standard of 0.45 (see Figure 1). The factor loading of all items was significant $(p<0.05)$. These results indicated that the threefactor scale structure was satisfactory (Horn and McArdle, 1992; Hu and Bentler, 1999). 


\section{A}

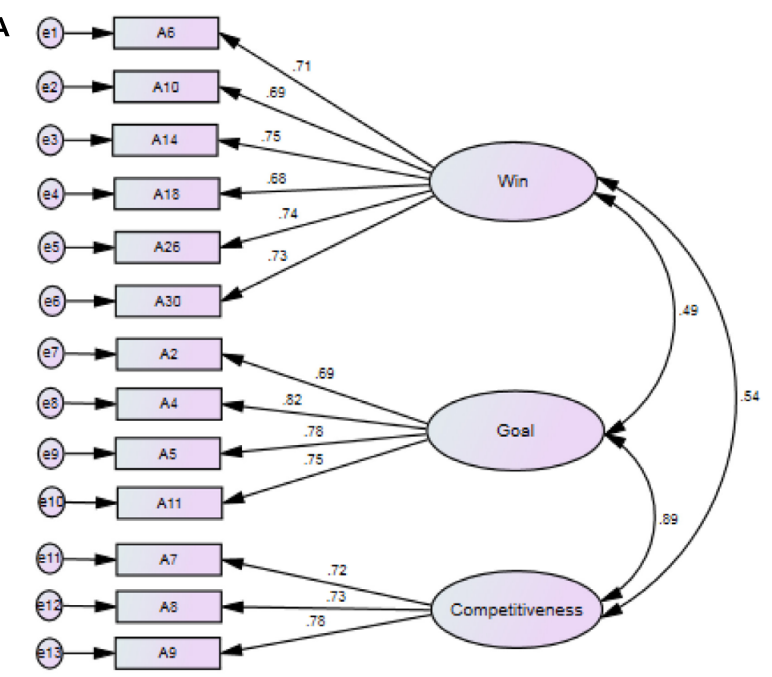

B

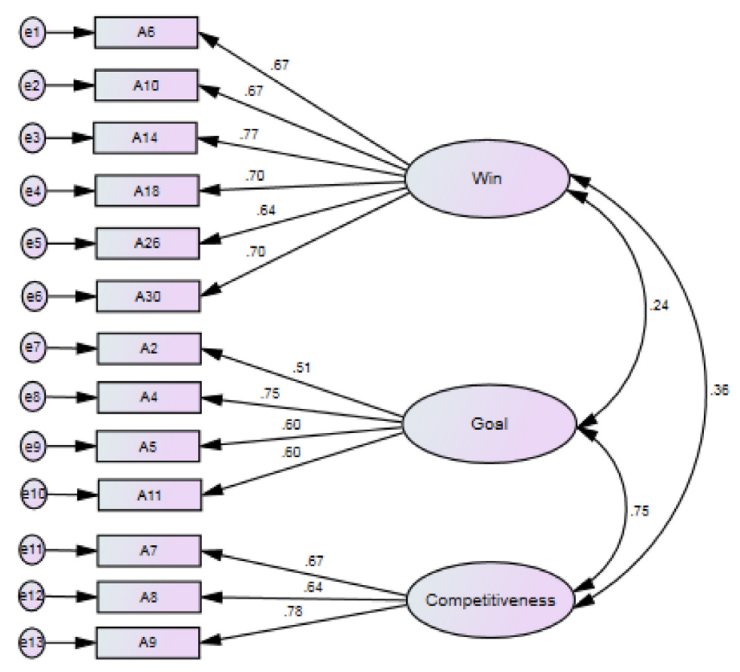

C

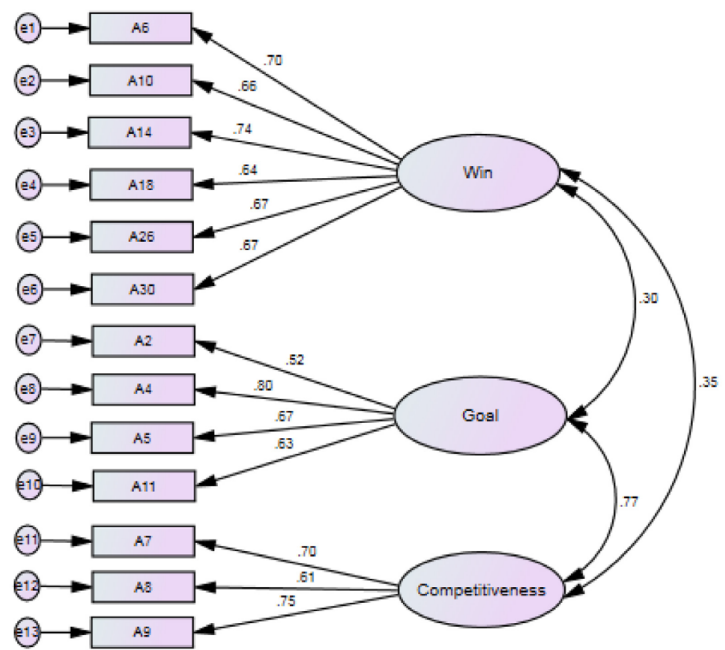

FIGURE 1 | Factor structure and standardized factor loading on sport orientation items. (A) Factor structure and standardized item loading for SOQ of Sample 2. (B) Factor structure and standardized item loading for SOQ of Sample 3. (C) Factor structure and standardized item loading for SOQ of Sample 4.

\section{Reliability of the SOQ-CA}

The data from samples 2, 3, and 4 were examined to test the internal consistency of the SOQ-CA (see Table 6). The results showed that win orientation $(0.86,0.87$, and 0.86 , respectively), goal orientation $(0.85,0.86$, and 0.80 , respectively), and the SOQCA overall $(0.89,0.90$, and 0.87 , respectively) scored above 0.80 . The competitiveness orientation was close to 0.80 in sample 2 (0.79) and sample 4 (0.78).

TABLE 6 | Internal consistency and test-retest reliability for the SOQ-CA.

\begin{tabular}{|c|c|c|c|c|}
\hline & $\begin{array}{c}\text { Cronbach's } \alpha \text { Sample } 2 \\
(n=336)\end{array}$ & $\begin{array}{c}\text { Cronbach's } \alpha \text { Sample } 3 \\
(n=338)\end{array}$ & $\begin{array}{c}\text { Cronbach's } \alpha \text { Sample } 4 \\
(n=338)\end{array}$ & $\begin{array}{l}\text { Test-retest reliability } \\
\text { Samples } 3 \text { and } 4 \\
\quad(n=338)\end{array}$ \\
\hline Win & 0.86 & 0.87 & 0.86 & 0.81 \\
\hline Goal & 0.85 & 0.86 & 0.80 & 0.76 \\
\hline Competitiveness & 0.79 & 0.80 & 0.78 & 0.76 \\
\hline SOQ-CA & 0.89 & 0.90 & 0.87 & 0.94 \\
\hline
\end{tabular}


The data from sample 3 and 4 were examined to validate the test-retest reliability of the SOQ-CA. The test-retest reliability was 0.81 for the win orientation, 0.76 for the goal orientation, 0.76 for the competitiveness orientation, and 0.94 for the SOQCA overall (see Table 6). All test-retest reliabilities scored above 0.75 , indicating that the SOQ-CA had higher stability (McGraw and Wong, 1996).

\section{Validity of the SOQ-CA}

To confirm the validity of the construct, correlations between the SOQ-CA and AMS-Sport were analyzed using data from samples 1 and 2. The results are presented in Table 7. The components of the SOQ-CA were correlated with the scales of the AMSSport. In both sample 1 and sample 2, the HS scales of the AMS-Sport correlated significantly with those of win orientation ( $r=0.35 ; r=0.37$, respectively), goal orientation $(r=0.53$; $r=0.54$, respectively), and competitiveness orientation $(r=0.51$; $r=0.53)$ of the SOQ-CA. Goal orientation $(r=0.17 ; r=0.16$, respectively) and competitiveness orientation ( $r=0.18$ for sample 2) also correlated with the FF scale of the AMS-Sport. There was no significant correlation between the win orientation and the FF in either sample 1 or sample 2 (see Table 7).

To further verify the construction of validity, different levels of physical activity were additionally examined (Litwin, 1995). In the context of the questionnaire, physical activity frequency was surveyed. The frequency of physical activity for $1 \mathrm{~h}$ or more and more than five times per week was defined as the active group; physical activity less than five times a week, or less than $1 \mathrm{~h}$ each time was defined as the general group. Univariate analysis of variance was performed on the data from samples $1,2,3$, and 4 . The ANOVA results show that the active group score was higher than that of the general group, with a significant difference visible in all samples (Table 8).

\section{DISCUSSION}

Based on the theoretical frameworks of Gill's SOQ, this study developed and validated a novel instrument to measure adolescent sport orientation in a Chinese context. The resulting SOQ-CA is composed of three scales (13 items total): win orientation (six items), goal orientation (four items), and competitiveness orientation (three items). Win orientation (i.e., items 6, 10, 14, 18, 26, and 30) assessed one's willingness to win. Goal orientation (i.e., items 2, 4, 5 , and 11) assessed one's sport goal-setting by winning a

TABLE 7 | Correlations between the scales of the SOQ-CA and AMS-Sport.

\begin{tabular}{lccllll}
\hline & \multicolumn{2}{c}{ Sample $\mathbf{1}(\boldsymbol{n}=\mathbf{1 5 0})$} & & \multicolumn{2}{c}{ Sample 2 $(\boldsymbol{n}=\mathbf{3 3 6})$} \\
\cline { 2 - 3 } \cline { 6 - 7 } & HS & FF & & HS & FF \\
\hline Win orientation & $0.35^{\star \star}$ & 0.10 & & $0.37^{\star \star}$ & 0.11 \\
Goal orientation & $0.53^{\star \star}$ & $0.17^{\star \star}$ & & $0.54^{\star \star}$ & $0.16^{\star \star}$ \\
Competitiveness & $0.51^{\star \star}$ & $0.16^{\star \star}$ & & $0.53^{\star \star}$ & & $0.18^{\star \star}$ \\
\hline
\end{tabular}

${ }^{* *} p<0.01$. game or sporting experience. Competitiveness (i.e., items 7, 8 , and 9) measured one's sense of competition by looking forward to the game, enjoying the game, and achieving the goal of the game.

In addition, the SOQ-CA shows satisfying test-control criteria. The internal consistency of the SOQ-CA scored above 0.80 and the retest reliability above 0.75 , indicating that the SOQCA has satisfactory validity and reliability (Barrow and McGoe, 1964; McGraw and Wong, 1996). The confirmatory analysis of the three samples also achieved satisfactory results (Tabachnick and Fidell, 2007). Further proof of the validity of the SOQCA construction is that the score of the active group is significantly higher than that of the general group. It indicates that the three-factor model is sufficient to measure the sport orientation in adolescents with different activity levels (Petróczi, 2003). However, the results of the CFA showed that the goal orientation and competitiveness factors were highly correlated (Rose et al., 1998). The reasons for this high correlation require further analysis.

Although the naming of the SOQ-CA subscales is consistent with Gill's SOQ, the measurement objective and goal of SOQCA are different from those of Gill's SOQ. Specifically, the goal of Gill's SOQ is to distinguish the athletic tendencies of elite athletes, while SOQ-CA focuses on youth. Gill's SOQ is more inclined to tap into the competitive potential of athletes, while the SOQ-CA tends to tap into the potential for student activity. It is worth mentioning that some previous studies have indicated that there are significant gender differences in sport orientation among elite athlete (Gill and Deeter, 1988; Findlay and Bowker, 2009; Jamshidi et al., 2011).

Another study has reported that there is no gender difference noted in either the competitiveness orientation (Martin et al., 1995) or the win orientation (Martin and Gill, 1995). This indicates controversy in regard to the issue of gender differences within sport orientation. However, this current study was not unable to address this issue.

In the construction of SOQ-CA, Chinese adolescents are more interested in factors winning (items 6, 14, and 26) than scoring (item 30). This seems to indicate that the act of winning itself is more important than winning more points. However, in interpreting these data to aid a particular adolescent, it is essential to consider whether winning is an important part of the sport (Manouchehri et al., 2013). Winning must be kept in perspective alongside other valuable aspects of youth sport, such as social development, fun, and fitness (David, 2019). Winning a competition is not a prerequisite for future life success, and it is more important to promote all three orientations, not merely winning, in whatever activity adolescents choose to do (Wigfield and Cambria, 2010). At the same time, as one of only three subscales in the SOQ-CA, the win orientation is also a necessary aspect of sport orientation in adolescents. This is consistent with Franken's view that the need to win tends to correlate with one's ego orientation (Franken and Brown, 1996). Malhotra (2010) argues that elements of the strategic environment can fuel competitive motivations and behaviors. The desire to win is further heightened when rivalry and time pressure coincide. Therefore, from an applied 
TABLE 8 | ANOVA among variables in samples 1, 2, 3, and 4.

\begin{tabular}{|c|c|c|c|c|c|}
\hline Samples & Group & Win & Goal & Competitiveness & SOQ \\
\hline \multirow[t]{4}{*}{1} & Active group $(n=17)$ & $24.59 \pm 5.24$ & $18.59 \pm 2.40$ & $13.88 \pm 1.32$ & $57.06 \pm 5.76$ \\
\hline & General group $(n=133)$ & $17.08 \pm 6.28$ & $16.05 \pm 4.15$ & $9.87 \pm 3.36$ & $43.00 \pm 10.71$ \\
\hline & $F$ & 22.28 & 6.06 & 23.59 & 28.14 \\
\hline & $P$ & $0.000^{\star \star \star}$ & $0.015^{\star}$ & $0.000^{\star \star \star}$ & $0.000^{\star \star \star}$ \\
\hline \multirow[t]{4}{*}{2} & Active group ( $n=30$ ) & $23.60 \pm 6.69$ & $17.97 \pm 3.85$ & $13.17 \pm 2.88$ & $54.73 \pm 12.40$ \\
\hline & General group $(n=306)$ & $16.48 \pm 6.3$ & $15.77 \pm 4.23$ & $9.50 \pm 3.44$ & $41.75 \pm 11.18$ \\
\hline & $F$ & 34.48 & 7.48 & 31.89 & 36.11 \\
\hline & $P$ & $0.000^{\star \star \star}$ & $0.007^{\star \star}$ & $0.000^{\star \star \star}$ & $0.000^{\star \star \star}$ \\
\hline \multirow[t]{4}{*}{3} & Active group ( $n=42)$ & $23.57 \pm 5.36$ & $18.12 \pm 2.27$ & $12.02 \pm 3.05$ & $53.71 \pm 7.97$ \\
\hline & General group $(n=296)$ & $17.30 \pm 5.85$ & $16.19 \pm 3.18$ & $10.11 \pm 3.01$ & $43.60 \pm 8.8$ \\
\hline & $F$ & 43.02 & 14.38 & 14.87 & 49.71 \\
\hline & $P$ & $0.000^{\star \star \star}$ & $0.000^{\star \star \star}$ & $0.000^{\star \star \star}$ & $0.000^{\star \star \star}$ \\
\hline \multirow[t]{4}{*}{4} & Active group ( $n=42)$ & $23.79 \pm 5.77$ & $18.40 \pm 2.41$ & $12.21 \pm 3.08$ & $54.40 \pm 8.95$ \\
\hline & General group $(n=296)$ & $17.25 \pm 5.57$ & $16.36 \pm 3.22$ & $10.04 \pm 3.03$ & $43.65 \pm 8.60$ \\
\hline & $F$ & 50.23 & 15.68 & 18.83 & 56.99 \\
\hline & $P$ & $0.000^{\star \star \star}$ & $0.000^{\star \star \star}$ & $0.000^{\star \star \star}$ & $0.000^{\star \star \star}$ \\
\hline
\end{tabular}

${ }^{*} p<0.05,{ }^{* *} p<0.01,{ }^{* * *} p<0.001$.

perspective, teachers and parents may find it beneficial to target individual interventions designed to enhance win ability (Jeffrey and Diane, 1995).

Competitiveness orientation is defined as a desire to enter and strive for success in sports competition (Martens, 1976; Vandewalle, 1997; Gill and Deeter, 1988; Kohn, 1992; Shields and Bredemeier, 2011). The concept of goal orientation, meanwhile, defines one's disposition toward developing or validating one's ability in achievement settings (Roberts and Ommundsen, 1996; Vandewalle, 1997; White et al., 1998). Individual goals serve as organizing principles, influencing the meaning of activities and how individuals respond to success (White and Zellner, 1996). In competitive sports situations, competitiveness orientation is influenced by individual differences and situational factors (Gill and Deeter, 1988; Martin and Gill, 1991). Meanwhile, the dimensions of goal orientation are constructed by recognizing the value of sports, goal-setting, working hard to win, and vibrancy in the activity. Compared to competitiveness orientation, goal orientation seems to be less affected by specific sport situations (Gill and Deeter, 1988). However, the SOQ-CA shows that competitiveness and goal orientations are highly correlated, which leads us to question the influence of both goal and competitiveness orientation (Newby and Klein, 2014; Clancy et al., 2016). Monacis et al. (2013) indicates that there is, in fact, a mediating effect between goal and competition orientations. Tari-Keresztes et al. (2015) state that sport situations cannot be ignored as a dimension of the construct of competitiveness orientation. In Gill's SOQ, competitiveness and goal orientations reflect ego orientation and task orientation as two separate motivators (Gill, 1993). However, competitiveness may become intrinsically connected to one's task orientation when it relates to internal goals or standards (Monacis et al., 2013). Consequently, one's task orientation in these circumstances may measure higher (Jensen,
1999; Jones et al., 2006; Wright et al., 2016). Future research should investigate the specific mechanism at play between goal orientation and competitiveness, especially focusing on the mediating role of sports situations.

Finally, one limitation of this study is the fact that our sample participants all came from the same geographic location, which means that our results cannot be assumed to represent all adolescents on a national scale without further verification. Additionally, this study limited participant age to 12-16 years. Future research should expand to include nationwide samples, a wider variety of ages, and different sport types (i.e., football, tennis, and jogging) to improve the questionnaire's reliability and validity better.

\section{CONCLUSION}

A novel 13-item short Chinese version of Sport Orientation Questionnaire (SOQ-CA) was developed based on the frameworks of Gill's original SOQ. With the analysis of data from Chinese youth, it has been proven to be a reliable and valid measure of sport orientation for Chinese adolescents. It can be used not only to assess daily exercise or physical education in class, but also for adolescent self-evaluation to assess daily exercise or physical education in class, as well as adolescent's self-evaluation regarding their extracurricular physical activities and competitive orientation.

\section{DATA AVAILABILITY STATEMENT}

The raw data supporting the conclusions of this article will be made available by the authors, without undue reservation, to any qualified researcher. 


\section{ETHICS STATEMENT}

This study was approved by the Scientific Ethics Committee of Academic Committee of the Southwest University. All parents/guardians signed a statement of consent authorizing the participation of their children. All the adolescents also signed the consent forms.

\section{AUTHOR CONTRIBUTIONS}

JC and YY: data collection, conception and design, data analysis, and writing the manuscript. NS: research design and critical revision.

\section{REFERENCES}

Alfermann, D., Geisler, G., and Okade, Y. (2013). Goal orientation, evaluative fear, and perceived coach behavior among competitive youth swimmers in Germany and Japan. Psychol. Sport Exerc. 14, 307-315. doi: 10.1016/j.psychsport.2012.11. 005

Allen, J., Taylor, J., Dimeo, P., Dixon, S., and Robinson, L. (2015). Predicting elite scottish athletes' attitudes towards doping: examining the contribution of achievement goals and motivational climate. J. Sports Sci. 33, 899-906. doi: 10.1080/02640414.2014.976588

Ames, C. (1992). Classroom goals, structures, and student motivation. J. Educ. Psychol. 84, 261-271.

Auxter, D., Pyfer, J., and Huettig, C. (2005). Principles and Methods Of Adapted Physical Education And Recreation. Dubuque, IA: McGraw-Hill.

Barker, C., Pistran, N., and Elliot, R. (1994). Research Methods in Clinical and Counselling Psychology. Chichester: Wiley.

Baron-Thiene, A., and Alfermann, D. (2015). Personal characteristics as predictors for dual career dropout versus continuation-A prospective study of adolescent athletes from German elite sport schools. Psychol. Sport Exerc. 21, 42-49. doi: 10.1016/j.psychsport.2015.04.006

Barrow, H. M., and McGoe, R. (1964). A Practical Approach to Measurement in Physical Education. Philadelphia: Lea \& Febiger.

Bentler, P. M., and Bonett, D. G. (1980). Significance tests and goodness-of-fit in the analysis of covariance structures. Psychol. Bull. 88, 588-600.

Bernstein, I. H., and Nunnally, J. C. (1994). Psychometric Theory. New York, NY: McGraw-Hill.

Biddle, S., Wang, C. J., Kavussanu, M., and Spray, C. (2003). Correlates of achievement goal orientations in physical activity: a systematic review of research. Eur. J. Sport Sci. 3, 1-20. doi: 10.1080/17461390300073504

Bolarinwa, O. A. (2015). Principles and methods of validity and reliability testing of questionnaires used in social and health science researches. Niger. Postgrad. Med. J. 22:195. doi: 10.4103/1117-1936.173959

Bowker, A., Gadbois, S., and Cornock, B. (2003). Sports participation and selfesteem: variations as a function of gender and gender role orientation. Sex Roles 49, 47-58.

Boynton, P. M., and Greenhalgh, T. (2004). Selecting, designing, and developing your questionnaire. BMJ 29, 1312-1315. doi: 10.1136/bmj.328.7451.1312

Brown, K. A., Patel, D. R., and Darmawan, D. (2017). Participation in sports in relation to adolescent growth and development. Transl. Pediat. 6:150. doi: 10.21037/tp.2017.04.03

Chang, J., Liu, X., and Yang, M. (2018). Development and validation of sports orientation questionnaire for chinese adolescent students. Med. Sci. Sports Exerc. 50:508. doi: 10.1249/01.mss.0000536756.42459.74

Chi, L., and Duda, J. L. (1995). Multi-sample confirmatory factor analysis of the task and ego orientation in sport questionnaire. Res. Q. Exer. Sport 66, 91-98. doi: 10.1080/02701367.1995.10762216

Clancy, R. B., Herring, M. P., MacIntyre, T. E., and Campbell, M. J. (2016). A review of competitive sport motivation research. Psychol. Sport Exerc. 27, 232-242. doi: 10.1016/j.psychsport.2016.09.003

\section{FUNDING}

This study was supported by the National Social Science Fund (15CTY011), the Fundamental Research Funds for the Central Universities of Southwest University (SWU1709240), and the Innovation Team Project (SWU1909105).

\section{ACKNOWLEDGMENTS}

We would like to thank the students and their parents who participated in this study, as well as the study staff for their support. In addition, we thank the reviewers' comments and suggestions.

Cronbach, L. J. (1951). Coefficient alpha and the internal structure of tests. Psychometrika 16, 297-334. doi: 10.1007/bf02310555

Daniel, J. M., Roberts, S. L., and Dohanich, G. P. (1999). Effects of ovarian hormones and environment on radial maze and water maze performance of female rats. Physiol. Behav. 66, 11-20. doi: 10.1016/s0031-9384(98)00272-8

Daniels, E., Sincharoen, S., and Leaper, C. (2005). The relation between sport orientations and athletic identity among adolescent girl and boy athletes. J. Sport Behav. 28:315.

David, A. F. (2019). The Role of Winning in Youth Sports. Youth Sports Research Council Rutgers. Camden, NJ: The State University of New Jersey.

Duda, J. L. (1989). Relationship between task and ego orientation and the perceived purpose of sport among high school athletes. J. Sport Exer. Psychol. 11, 318335. Available online at: http://journals.humankinetics.com.ezproxy.lakeheadu. $\mathrm{ca} / J S E P$

Duda, J. L. (1993). "Goals: a social-cognitive approach to the study of achievement motivation in sport," in Handbook of Research On Sport Psychology, eds R. N. Singer, M. Murphey, and L. K. Tennant (New York, NY: Macmillan), 421-436.

Duda, J. L. (1995). "Motivation in sport settings: a goal perspective approach," in Motivation in Sport And Exercise, ed. G. C. Roberts (Totowa, NJ: Human Kinetics), 57-91.

Duda, J. L., and White, S. A. (1992). Goal orientations and beliefs about the causes of sport success among elite skiers. Sport Psychol. 6, 334-343. doi: 10.1123/tsp. 6.4.334

Duda, J. L., and Whitehead, J. (1998). Measurement of goal perspectives in the physical domain. Ad. Sport Exer. Psychol. Meas. 172.

Dweck, C. S. (1986). Motivational processes affecting learning. Am. Psychol. 41, 1040-1048. doi: 10.1037/0003-066X.41.10.1040

Elbe, A. M., and Wenhold, F. (2005). Cross-cultural test-control criteria for the achievement motives scale-sport. Intern. J. Sport Exerc. Psychol. 3, 163-177. doi: 10.1080/1612197x.2005.9671765

Esbensen, K. H., Guyot, D., Westad, F., and Houmoller, L. P. (2002). Multivariate Data Analysis: In Practice: An Introduction To Multivariate Data Analysis And Experimental Design. Oslo, NO: Multivariate Data Analysis.

Farshad, T., Jasem, M., Shahram, N., and Mohammad, M. (2013). Validation of an instrument for measuring athletes' sport orientation in Iranian martial artists community. Middle East J. Sci. Res. 18, 738-743.

Field, A. (2009). Discovering Statistics Using SPSS. New York, NY: Sage publications. Findlay, L. C., and Bowker, A. (2009). The link between competitive sport participation and self-concept in early adolescence: a consideration of gender and sport orientation. J. Youth Adolesc. 38, 29-40. doi: 10.1007/s10964-0079244-9

Findlay, L. C., and Coplan, R. J. (2008). Come out and play: shyness in childhood and the benefits of organized sports participation. Can. J. Behav. Sci. 40:153. doi: 10.1037/0008-400x.40.3.153

Franken, R. E., and Brown, D. J. (1996). The need to win is not adaptive: the need to win, coping strategies, hope and self-esteem. Pers. Individ. Differ. 20, 805-808. doi: 10.1016/0191-8869(96)00026-8

Gill, D. L. (1993). Competitiveness and competitive orientation in sport. Handb. Res. Sport Psychol. 13, 314-327. 
Gill, D. L., and Deeter, T. E. (1988). Development of the sport orientation questionnaire. Res. Q. Exerc. Sport 59, 191-202. doi: 10.1080/02701367.1988. 10605504

Gill, D. L., and Dzewaltowski, D. A. (1988). Competitive orientations among intercollegiate athletes: Is winning the only thing? Sport Psychol. 2, 212-221. doi: $10.1123 /$ tsp.2.3.212

Gill, D. L., Williams, L., Dowd, D. A., Beaudoin, C. M., and Martin, J. J. (1996). Competitive orientations and motives of adult sport and exercise participants. Cell 19, 307-318.

Gutiérrez, M., Caus, N., and Ruiz, L. M. (2011). The influence of parents on achievement orientation and motivation for sport of adolescent athletes with and without disabilities. J. Leisure Res. 43, 355-382. doi: 10.1080/00222216. 2011.11950241

Han, J., Waddington, G., Anson, J., and Adams, R. (2015). Level of competitive success achieved by elite athletes and multi-joint proprioceptive ability. J. Sci. Med. Sport 18, 77-81. doi: 10.1016/j.jsams.2013.11.013

Hanrahan, S., and Biddle, S. (2002). Measurement of achievement orientations: psychometric measures, gender, and sport differences. Eur. J. Sport Sci. 2, 1-12. doi: $10.1080 / 17461390200072502$

Hayashi, C. T., and Weiss, M. R. (1994). A cross-cultural analysis of achievement motivation in Anglo-American and Japanese marathon runners. Int. J. Sport Psychol. 25, 187-202.

Horn, J. L., and McArdle, J. J. (1992). A practical and theoretical guide to measurement invariance in aging research. Exp. Aging Res. 18, 117-144. doi: $10.1080 / 03610739208253916$

Hu, J., and Bentler, P. M. (1999). Cutoff criteria for fit indexes in covariance structure analysis: conventional criteria versus new alternatives. Struct. Equat. Model. 6, 1-55. doi: 10.1080/107055199095 40118

Jamshidi, A., Hossien, T., Sajadi, S. S., Safari, K., and Zare, G. (2011). The relationship between sport orientation and competitive anxiety in elite athletes. Proc. Soc. Behav. Sci. 30, 1161-1165. doi: 10.1016/j.sbspro.2011.10.226

Jeffrey, J., and Diane, L. (1995). Competitive orientation, self-efficacy and goal importance in Filipino marathoners. Int. J. Sport Psychol. 26, 348-358.

Jensen, S. L. (1999). The relationship between perfectionism, eating disorders, and participation motivation among female distance runners. Min. Pediatr. 58:1528.

Jones, G., and Swain, A. (1992). Intensity and direction as dimensions of competitive state anxiety and relationships with competitiveness. Percept. Mot. Skills 74, 467-472. doi: 10.2466/pms.1992.74.2.467

Jones, G. W., Mackay, K. S., and Peters, D. M. (2006). Participation motivation in martial artists in the West Midlands region of England. J. Sports Sci. Med. $5: 28$

Kang, L., Gill, D. L., Acevedo, E. O., and Deeter, T. E. (1990). Competitive orientations among athletes and non-athletes in Taiwan. Intern. J. Sport Psychol. $21,146-157$.

Kim, B. J., and Gill, D. L. (1997). A cross-cultural extension of goal perspective theory to Korean youth sport. J. Sport Exerc. Psychol. 19, 142-155. doi: 10.1123/ jsep.19.2.142

Kjønniksen, L., Anderssen, N., and Wold, B. (2009). Organized youth sport as a predictor of physical activity in adulthood. Scand. J. Med. Sci. Sports 19, 646-654. doi: 10.1111/j.1600-0838.2008.00850.x.

Kohn, A. (1992). No contest: The Case Against Competition. Boston: Houghton Mifflin.

Kokaridas, D., Perkos, S., Harbalis, T., and Koltsidas, E. (2009). Sport orientation and athletic identity of Greek wheelchair basketball players. Percept. Mot. Skills 109, 887-898. doi: 10.2466/pms.109.3.887-898

Kolt, G. S., Driver, R. P., and Giles, L. C. (2004). Why older Australians participate in exercise and sport. J. Aging Phys. Activ. 12, 185-198. doi: 10.1123/japa.12.2. 185

Koumpoula, M., Tsopani, D., Flessas, K., and Chairopoulou, C. (2011). Goal orientations and sport motivation, differences between the athletes of competitive and non-competitive rhythmic gymnastics. J. Sport Med. Phys. Fit. $51,480-488$

Lata, J., and Mondello, M. (2010). An analysis of goal achievement orientation and sport morality levels of division IA nonrevenue collegiate athletes. J. Study Sports Athletes Educ. 4, 69-94. doi: 10.1179/ssa.2010.4.1.69
Lerner, B. S., and Locke, E. A. (1995). The effects of goal setting, self-efficacy, competition, and personal traits on the performance of an endurance task. $J$. Sport Exerc. Psychol. 17, 138-152. doi: 10.1123/jsep.17.2.138

Lewthwaite, R., and Piparo, A. J. (1993). Goal orientations in young competitive athletes: physical achievement, social-relational, and experiential concerns. J. Res. Pers. 27, 103-117. doi: 10.1006/jrpe.1993.1007

$\mathrm{Li}, \mathrm{K}$, and Tang, H. (1990). Validation and revision sport orientation questionnaire (SOQ). Hubei Sports Sci. 10, 15-18.

Lihui, L. (2004). The relationship between P .E .teaching materials and college students' sports tendency. J. Wuhan Instit. Phys. Educ. 38, 141-142.

Litwin, M. S. (1995). How to Measure Survey Reliability And Validity. New York, NY: Sage.

Lochbaum, M., Kazak Çetinkalp, Z., Graham, K. A., Wright, T., and Zazo, R. (2016). Task and ego goal orientations in competitive sport: a quantitative review of the literature from 1989 to 2016. Kinesiology 48, 3-29. doi: 10.26582/ k.48.1.14

Maehr, M. L., and Braskamp, L. A. (1986). The Motivation Factor: A Theory of Personal Investment. Lanham, MY: Lexington Books/DC Heath and Company.

Malhotra, D. (2010). The desire to win: the effects of competitive arousal on motivation and behavior. Organ. Behav. Hum. Decis. Process. 111, 139-146. doi: 10.1016/j.obhdp.2009.11.005

Manouchehri, J., and Tojari, F. (2013). Examining the conceptual model: relationships between sport orientation, doping attitude and doping behavior in iranian elite martial artists. Eur. J. Exp. Biol. 3, 175-182.

Manouchehri, J., Tojari, F., and Ganjouei, F. A. (2013). Variance analysis: doping attitude, doping behavior and sport orientation in elite martial artists. Eur. J. Exp. Biol. 3, 62-67.

Marsh, H. W. (1994). Sport motivation orientations: beware of jingle-jangle fallacies. J. Sport Exerc. Psychol. 16, 365-380. doi: 10.1123/jsep.16.4.365

Marsh, H. W., Perry, C., Horsely, C., and Roche, L. (1995). Multidimensional selfconcepts of elite athletes: How do they differ from the general population? J. Sport Exerc. Psychol. 17, 70-83. doi: 10.1123/jsep.17.1.70

Martens, R. (1976). "Competition: in need of a theory," in Social Problems In Athletics, ed. D. M. Landers (Urbana: University of Illinois Press), 9-17.

Martin, J. J., Adams-Mushett, C., and Smith, K. L. (1995). Athletic identity and sport orientation of adolescent swimmers with disabilities. Adapt. Phys. Activ. Q. 12, 113-123. doi: 10.1123/apaq.12.2.113

Martin, J. J., and Gill, D. L. (1991). The relationships among competitive orientation, sport-confidence, self-efficacy, anxiety, and performance. J. Sport Exerc. Psychol. 13, 149-159. doi: 10.1123/jsep.13.2.149

Martin, J. J., and Gill, D. L. (1995). The relationships of competitive orientations and self-efficacy to goal importance, thoughts, and performance in high school distance runners. J. Appl. Sport Psychol. 7, 50-62. doi: 10.1080/ 10413209508406300

McGraw, K. O., and Wong, S. P. (1996). Forming inferences about some intraclass correlation coefficients. Psychol. Methods 1:30. doi: 10.1037/1082-989x.1.1.30

Mehta, S., Bastero-Caballero, R. F., Sun, Y., Zhu, R., Murphy, D. K., Hardas, B., et al. (2018). Performance of intraclass correlation coefficient (ICC) as a reliability index under various distributions in scale reliability studies. Statist. Med. 37, 2734-2752. doi: 10.1002/sim.7679

Miller, S. M., and Siegel, J. T. (2017). Youth sports and physical activity: the relationship between perceptions of childhood sport experience and adult exercise behavior. Psychol. Sport Exerc. 33, 85-92. doi: 10.1016/j.psychsport. 2017.08.009

Mills, B. D. (1996). The relationship between middle school aged students goal orientation, self-confidence and competitive sport experience. J. Hum. Mov. Stud. 31, 39-45.

Monacis, L., Estrada, O., Sinatra, M., Tanucci, G., and de Palo, V. (2013). Selfdetermined motivation, sportspersonship, and sport orientation: a mediational analysis. Proc. Soc. Behav. Sci. 89, 461-467. doi: 10.1016/j.sbspro.2013. 08.878

Newby, J. L., and Klein, R. G. (2014). Competitiveness reconceptualized: psychometric development of the competitiveness orientation measure as a unified measure of trait competitiveness. Psychol. Record 64, 879-895. doi: 10.1007/s40732-014-0083-2

Newton, M., and Duda, J. L. (1993). The relationship of task and ego orientation to performance-cognitive content, affect, and attributions in bowling. J. Sport Behav. 16, 209-209. 
Nicholls, J. G. (1989). The Competitive Ethos and Democratic Education. Cambridge, MA: Harvard University Press.

Paiva, P. C. P., Paiva, H. N. D., Oliveira Filho, P. M. D., Lamounier, J. A., and Ferreira, E. F. E. (2014). Development and validation of a social capital questionnaire for adolescent students (SCQ-AS). PLoS One 9:e103785. doi: 10.1371/journal.pone.0103785

Patton, M. Q. (1999). Enhancing the quality and credibility of qualitative analysis. Health Serv. Res. 34, 1189-1208.

Perkins, D. F., and Borden, L. (2004). "Making collaborations work for children, youth, and families," in Proceedings of the 20th AIAEE Annual Conference, Dublin.

Petróczi, A. (2003). Exploring the Doping Dilemma In Elite Sport: Can Athletes' Attitudes Be Responsible For Doping? Greeley: University of Northern Colorado.

Petróczi, A. (2007). Attitudes and doping: a structural equation analysis of the relationship between athletes' attitudes, sport orientation and doping behaviour. Subst. Abuse Treat. Prevent. Policy 2:34.

Pons, F., Mourali, M., and Nyeck, S. (2006). Consumer orientation toward sporting events: scale development and validation. J. Serv. Res. 8, 276-287. doi: 10.1177/ 1094670505283931

Roberts, G. C. (1992). Motivation in sport and exercise: Constraints and conceptual convergence. Motivation in sport and exercise. Hum. Kinet. 18, 264-280.

Roberts, G. C., and Balagué, G. (1989). The Development of a Social-cognitive Scale in Motivation. Singapore: In Seventh World Congress of Sport Psychology.

Roberts, G. C., and Ommundsen, Y. (1996). Effect of goal orientation on achievement beliefs, cognition and strategies in team sport. Scand. J. Med. Sci. Sports 6, 46-56. doi: 10.1111/j.1600-0838.1996.tb00070.x

Rose, B., Larkin, D., and Berger, B. G. (1998). The importance of motor coordination for children's motivational orientations in sport. Adapt. Phys. Activ. Q. 15, 316-327. doi: 10.1123/apaq.15.4.316

Scoffier, S., Gernigon, C., and d'Arripe-Longueville, F. (2012). Effects of achievement goals on self-regulation of eating attitudes among elite female athletes: an experimental study. Psychol. Sport Exerc. 13, 201-207. doi: 10.1016/ j.psychsport.2011.11.005

Seifriz, J., Duda, J. L., and Chi, L. (1992). The relationship of perceived motivational climate to intrinsic motivation and beliefs about success in basketball. J. Sport Exerc. Psychol. 14, 375-391. doi: 10.1123/jsep.14.4.375

Sheikh, M., Afshari, J., and Sheikh, H. (2011). Comparing sport orientation between individual and team sport, and it is relation to sport participation motivation. Am. J. Sci. Res. 30, 28-35.

Shields, D., and Bredemeier, B. (2011). Contest, competition, and metaphor. J. Philos. Sport 38, 27-38. doi: 10.1080/00948705.2011.9714547

Shihui, C., Jin, W., Mei, J., and On, L. K. (2007). Motivation of sport participation in elite athletes with physical disabilities in mainland china. Asian J. Exerc. Sports Sci. 78:4.

Singh, A. S., Vik, F. N., Chinapaw, M. J., Uijtdewilligen, L., Verloigne, M., and Fernández-Alvira, J. M. (2011). Test-retest reliability and construct validity of the ENERGY-child questionnaire on energy balance-related behaviours and their potential determinants: the ENERGY-project. Intern. J. Behav. Nutr. Phys. Activ. 8:136. doi: 10.1186/1479-5868-8-136

Skordilis, E. K., Koutsouki, D., Asonitou, K., Evans, E., Jensen, B., and Wall, K. (2001). Sport orientations and goal perspectives of wheelchair athletes. Adapt. Phys. Activ. Q. 18, 304-315. doi: 10.1123/apaq.18.3.304

Skordilis, E. K., Skafida, F. A., Chrysagis, N., and Nikitaras, N. (2006). Comparison of sport achievement orientation of male wheelchair basketball athletes with congenital and acquired disabilities. Percept. Mot. Skills 103, 726-732. doi: 10.2466/pms.103.3.726-732

Skordilis, E. K., and Stavrou, N. A. (2005). Sport orientation model for wheelchair basketball athletes. Percept. Mot. Skills 100, 1081-1096. doi: 10.2466/pms.100. 3c.1081-1096

Stipek, D. J. (1988). Motivation to Learn: From Theory to Practice. Englewood Cliffs, NJ: Prentice Hall.

Sum, R. K. W., Ha, A. S. C., Cheng, C. F., Chung, P. K., Yiu, K. T. C., Kuo, C. C., et al. (2016). Construction and validation of a perceived physical literacy instrument for physical education teachers. PLoS One 11:e0155610. doi: 10.1371/journal. pone. 0155610
Swann, C., Moran, A., and Piggott, D. (2015). Defining elite athletes: issues in the study of expert performance in sport psychology. Psychol. Sport Exerc. 16, 3-14. doi: 10.1016/j.psychsport.2014.07.004

Tabachnick, B. G., and Fidell, L. S. (2007). Using Multivariate Statistics. Boston, MA: Allyn \& Bacon.

Tari-Keresztes, N., Pikó, B., and Fülöp, M. (2015). Does competitiveness count? The role of competitive attitudes in health risk and preventive health behaviours. Eur. J. Ment. Health 10, 44-61. doi: 10.5708/ejmh.10.2015.1.3

Telama, R., Yang, X., Hirvensalo, M., and Raitakari, O. (2006). Participation in organized youth sport as a predictor of adult physical activity: a 21-year longitudinal study. Pediatr. Exerc. Sci. 18, 76-88. doi: 10.1123/pes.18.1.76

Treasure, D. C., and Roberts, G. C. (1994). Cognitive and affective concomitants of task and ego goal orientations during the middle school years. J. Sport Exerc. Psychol. 16, 15-28. doi: 10.1123/jsep.16.1.15

Trembath, E. M., Szabo, A., and Baxter, M. J. (2002). Participation motives in leisure center physical activities. Athletic Insight 4, 28-41.

Vandewalle, D. (1997). Development and validation of a work domain goal orientation instrument. Educ. Psychol. Measur. 57, 995-1015. doi: 10.1177/ 0013164497057006009

Vealey, R. S. (1986). Conceptualization of sport-confidence and competitive orientation: Preliminary investigation and instrument development. J. Sport Psychol. 8, 221-246. doi: 10.1123/jsp.8.3.221

Vilkas, A., and Mëlinis, R. (2017). Peculiarities of the changes in physical activity and sport orientation of 5th-10th grade learners. Pedagogika 128, 232-247.

Wakayama, H., Watanabe, E., and Inomata, K. (2002). Exploratory factor analysis of the sport orientation questionnaire and the task and ego orientation in sport questionnaire in a japanese sport setting. Percept. Mot. Skills 95, 1179-1186. doi: $10.2466 /$ pms.2002.95.3f.1179

Weiner, B. (1985). An attributional theory of achievement motivation and emotion. Psycho. Rev. 92:548. doi: 10.1037/0033-295x.92.4.548

White, S. A., Duda, J. L., and Keller, M. R. (1998). The relationship between goal orientation and perceived purposes of sport among youth sport participants. J. Sport Behav. 21:474.

White, S. A., and Zellner, S. R. (1996). The relationship between goal orientation, beliefs about the causes of sport success, and trait anxiety among high school, intercollegiate, and recreational sport participants. Sport Psychol. 10, 58-72. doi: $10.1123 /$ tsp.10.1.58

Wigfield, A., and Cambria, J. (2010). Achievement motivation. Corsini Encycl. Psychol. 1-2. doi: 10.1002/9780470479216.corpsy0008

World Health Organization [WHO] (2019). Physical Inactivity: A Global Public Health Problem. Geneva: WHO.

Wright, B. J., O'Halloran, P. D., and Stukas, A. A. (2016). Enhancing selfefficacy and performance: an experimental comparison of psychological techniques. Res. Q. Exerc. Sport 87, 36-46. doi: 10.1080/02701367.2015.109 3072

Xu, J., and Gao, C. (2018). Physical activity guidelines for Chinese children and adolescents: the next essential step. J. Sport Health Sci. 7:120. doi: 10.1016/j. jshs.2017.07.001

Yin, X. C. (2002). Discussion on the relationship between teaching material of track and field and students' exercise tendency. Sichuan Sports Sci. 21, 58-59. doi: 10.13932/j.cnki.sctykx.2002.04.029

Zarghmi, M., Ghamary, A., ShaykhShabani, S., and Varzaneh, A. (2010). Perfectionism and achievement goals in adult male elite athletes who compete at the national level and above. J. Hum. Kinet. 26, $147-154$.

Conflict of Interest: The authors declare that the research was conducted in the absence of any commercial or financial relationships that could be construed as a potential conflict of interest.

Copyright (c) 2020 Chang, Yi and Song. This is an open-access article distributed under the terms of the Creative Commons Attribution License (CC BY). The use, distribution or reproduction in other forums is permitted, provided the original author(s) and the copyright owner(s) are credited and that the original publication in this journal is cited, in accordance with accepted academic practice. No use, distribution or reproduction is permitted which does not comply with these terms. 